\title{
The rights of voluntary patients in hospital
}

\author{
Philip Sugarman and Julla Moss
}

\begin{abstract}
The law in England and Wales regarding consent to treatment is of some complexily, but if remains true that hospltal patients have two basic ifghts: to refuse treatment of any kind, and to leave hospltal. Two hundred and seven teaching hospltal in-patients were asked about their care, and what would happen if they exercised these ifghts. Informal poychiatilic patients were the most likely to disagree with their treatiment in hospltal, while almost haif of all patients did not know that they had the right to refuse $\mathrm{H}$. Many anticipated coerctie responses from staff. Patients in hospltal should bo better informed of their inghts.
\end{abstract}

Informal psychiatric patients are admitted to hospital on a voluntary basis, at least in law (Hoggett, 1990). Once there, they may be subject to a range of interventions and restrictions, commonly including the administration of powerful drugs, and curtailment of freedom and activities. This may all serve the patient's best interests, but none of it can occur without the individual's consent (Mackay, 1990). Indeed any intervention without consent constitutes battery. The only exceptions to this legal doctrine are the treatment of minors, unconscious patients, and persons legally incapable of giving consent.

As patients are generally cooperative, consent to residence and treatment in hospital is often assumed. However, for such implied consent to be valid, the person must be accepting treatment voluntarily, i.e. not be under coercion. Further, implied consent is surely valid only if the patient is at least aware of the option of declining treatment. Put more simply, voluntary patients in hospital have the right to refuse any treatment they do not like, and the right to leave hospital (Hoggett, 1990). We decided to determine how many informal psychiatric patients in hospital agree that they need their current treatment and care, how many know they have the right to decline it, and how many anticipate coercion if they exercise that right.

\section{The study}

After approval by local ethics committees, all informal psychiatric patients in two large teach- ing hospitals were surveyed, including psychogeriatric patients. All patients on the medical and surgical wards of one of these hospitals were taken as a comparison group (excluding paediatric and geriatric patients). With the agreement of nursing staff, we approached each patient possibly able to cooperate. An explanation of the study was given before express verbal consent was sought. Interviewees were asked a series of questions, being prompted to give categorical responses when required.

\section{Findings}

On 273 patients, 207 were interviewed. Apparent dementia or a lowered level of consciousness was the commonest reason for non-participation in both groups (see Table 1). Explicit withholding of consent on approach occurred only twice, although more often patients declined to answer particular questions.

Psychiatric patients were significantly younger than their medical and surgical counterparts, while the slight excess of female psychiatric patients was not significant. Overall, responses fell well short of those expected of an Ideal group of truly voluntary and fully informed patients. Psychiatric patients were less likely to perceive any need for their treatment or the need to be in hospital, and were much more inclined to exercise any wish toward refusing treatment or leaving. A substantial number of patients in both groups anticipated being instructed. pressurised or restrained if they tried to do so. Some psychiatric and medical patients (but no surgical) mentioned possible detention under the Mental Health Act. Less than two thirds of all patients thought they had the right by law to leave hospital, and only just over half the right by law to refuse treatment. On non-psychiatric wards, more women than men agreed with the need for treatment (in fact only one disagreed), and fewer knew of the right to refuse it. Stepwise regression analysis suggested that age did not account for the differences between specialties and between the sexes. 
ORIGINAL PAPERS

Table 1. Teaching hospital in-patients' responses

\begin{tabular}{|c|c|c|}
\hline Speciallity & Modicol/surgical & Pyychiatilic \\
\hline $\begin{array}{l}\text { Original sample } \\
\text { Able and consenting } \\
\text { Male } \\
\text { Female } \\
\text { Mean age (years) } \\
\text { Percentage positive responses } \\
\text { 1. Do you think you need to be in hospltal at the moment? }\end{array}$ & $\begin{array}{l}131 \\
90 \\
47 \\
43 \\
70.1 \\
84\end{array}$ & $\begin{array}{l}142 \\
117 \\
54 \\
63 \\
54.0^{\circ} \\
68^{\circ}\end{array}$ \\
\hline 2. Do you think you need the treatment you're having? & $91^{x}$ & $79 c$ \\
\hline 3. If you really wanted to, would you leave the hospital? & 33 & $56^{\circ}$ \\
\hline 4. If you really wanted to, would you refuse a treatment? & 23 & $46^{\circ}$ \\
\hline $\begin{array}{l}\text { 5. If you insisted on leaving the hospital, what would happen? } \\
\text { Patient anticipates non-coerclve response }\end{array}$ & 76 & 67 \\
\hline $\begin{array}{l}\text { 6. If you refused to have your treatment, what would happen? } \\
\text { Patient anticipates non-coercive response }\end{array}$ & 62 & 62 \\
\hline 7. As far as you know, do you have the right by law to leave hospltal? & 67 & 63 \\
\hline $\begin{array}{l}\text { 8. As far as you know, do you have the right by law to refuse treatment? } \\
\text { a difference between specialties, } P<0.001 \\
\text { " difference between specialties, } P<0.01 \\
\text { " difference between specialties, } P<0.05 \\
\text { × more women answered yes, } P<0.05 \\
\text { y more women answered no, } P<0.05\end{array}$ & $50^{y}$ & 55 \\
\hline
\end{tabular}

\section{Comment}

The dissatisfaction with services of many psychiatric patients has recently been highlighted in a survey by MIND, the National Association for Mental Health (Rogers et al, 1993). In particular, $52 \%$ of patients reported, in retrospect, having received unwanted treatment at some time, and $80 \%$ considered they had not received enough information about their treatment generally. These data were collected after 1000 interview schedules were sent out to MIND regional offices and other contacts, and 516 returned by a wide variety of interviewers. The present study reports interviews by the authors of current teaching hospital in-patients, and is not subject to the risk of bias towards picking up complaints, which clouds the MIND survey. Indeed, teaching hospitals are generally supposed to lead in health care so that these results may reflect the state of the art in psychiatric practice.

We found, however, that informal psychiatric patients often do not agree that they need their treatment in hospital. Many envisage refusing it or leaving, even though, like medical and surgical patients, they may be unaware of their rights to do so, and may anticipate coercion. Some of these problems might be attributed to mental disorder, to widespread attitudes toward mental health issues, or to the failings of medicine in general. Our finding of gender differences suggests that wider cultural factors are important, at least in non-psychiatric settings.

A partial solution may lie in improving patients' access to information. Informal psychiatric patients should not only have the proposed treatment in hospital properly explained, but also be informed of their basic right to give or withhold consent to it. At present only those detained under the Mental Health Act are provided by law with written and oral information about their rights. However, a similar leaflet for informal psychiatric patients has been designed (Sugarman \& Long, 1992), and our findings suggest that non-psychiatric patients would also benefit from such information*. We believe that better information for patients is essential, as part of the move to a more patient-oriented health service.

*Leaflets for all voluntary patients, irrespective of specialty, are now avallable. Printed in both in English and minority languages, these outline patients' rights. and also explain complaints procedures, as required by the Hospital Complaints Procedures Act 1985. Details are avallable from Carole Dowell at Reaside Clinic. Birmingham B45 9BE (telephone 0214536161 , extension 279). 


\section{Acknowledgement}

We would like to thank Professor R. Bluglass for his comments on an earlier draft of this paper.

\section{References}

Hoggett, B. (1990) Mental Health Law. Third edition. London: Sweet \& Maxwell.

MACKAY, R.D. (1990) Consent to treatment. In Principles and Practice of Forenstc Psychiatry. (eds. R. Bluglass
\& P. Bowden). Pp 1149-1162. Edinburgh: Churchill Livingstone.

Rogers A. PLLRIM, D. \& LACEY, R. (1993) Expertencting Psychtatry. Users' view of services. London: MacMillan.

Sugarman, P.A. \& LONG. A. (1992) Informing voluntary patients of their rights. Psychiatric Bulletin. 16, 1477.

Philip Sugarman, Senior Registrar in Forensic Psychiatry; and Julia Moss, Registrar, Reaside Clinic, Birmingham B45 9BE

\title{
'A ward in a street'
}

\author{
N. Kaye and D.I. Khoosal
}

\begin{abstract}
Attempts to dellver quallty service outside the traditional mental hosplital to those with chronic mental illness have resulted in several new models of care. We describe one such model of alternative care and asylum. Considerable improvements in quality of life, quallty of care and clinical state occurred.
\end{abstract}

Carlton Hayes Hospital is a mental hospital in the village of Narborough on the outskirts of Leicester. It originally served as the county asylum. By the late 1970s the existing facilities for rehabilitation had been successful in discharging many patients but left a 'hard core' of longstay patients who needed high levels of nursing and psychiatric care. To meet the needs of these patients we decided to extend the concept of the 'ward in a house' (hostel ward) (Wing \& Wykes 1982), to a 'ward in a street'. We placed patients in upgraded staff houses, adjacent to the hospital and surplus to requirement, where full care could be offered in domestic accommodation. We hoped the enhanced facilities would improve quality of life and might lead to a breakthrough in rehabilitation. The new unit was called the New Rutland Unit (NRU).

\section{Description}

The unit was opened in June 1989. It is scattered in clusters over a quarter mile in a residential area, with a history of acceptance and tolerance of our patients. There are three components.

(a) Five pairs of semi-detached, selfcontained houses. There are three patients to a house, each with a single bedroom. A telephone connects to the hospital switchboard.

(b) Langton House - a redundant nurses' home on the edge of the hospital campus. with eight single bedrooms and communal facilities. This was first used for patients for whom there was greatest uncertainty about their ability to cope and later as an assessment unit for new entrants.

(c) Two nursing stations, one in Langton House and the other in the farthest row of houses.

\section{Planning}

Six months before the opening a multidisciplinary planning team was formed. The chief task was to carry out multidisciplinary assessments of the 41 patients on the old (Rutland) ward, all of whom were potentially eligible for the new unit. These patients, most with schizophrenia, were the least disturbed and incompetent of the five graduate, non-dementia wards. We excluded five patients, one with intractable violent behaviour, two who could not climb stairs and two who refused to leave the main hospital. One was formally detained (Home Office Order). The unit was to be tested as a model of care for those whose quality of life might be improved even if discharge was unlikely. This was a major departure from the frequent practice of making the offer of improved living conditions contingent on progress towards discharge. The principle remains a benchmark for the unit. The administration found it necessary to insist on transfer of all 36 patients with their staff and closure of 